\title{
Water-resistant surfaces using zinc oxide structured nanorod arrays with switchable wetting property
}

\author{
Houda Ennaceri ${ }^{(1,2)^{*}}$, Lan Wang ${ }^{3}$, Darja Erfurt ${ }^{4}$, Abdelhafed Taleb ${ }^{(5,6)}$, Asmae Khaldoun ${ }^{2}$, Abdallah El \\ Kenz $^{1}$, Abdelilah Benyoussef ${ }^{1}$, Ahmed Ennaoui ${ }^{(3,7,8)}$ \\ ${ }^{1}$ Laboratory of Magnetism and Physics of High Energies, URAC 12, Department of Physics, B.P. 1014, Faculty of \\ Sciences, Mohammed V- Agdal University, Rabat, Morocco \\ ${ }^{2}$ School of Science and Engineering, Al Akhawayn University, B.O. Box 104, Ifrane 53000, Morocco \\ ${ }^{3}$ Helmholtz-Zentrum Berlin für Materialien und Energie, Hahn Meitner Platz 1, 14109 Berlin, Germany \\ ${ }^{4}$ Technical University of Berlin (TU-Berlin), Straße des 17. Juni 135, 10632, Berlin, Germany \\ ${ }_{5}^{5}$ PSL Research University, Chimie ParisTech - CNRS, Institut de Recherche de Chimie Paris, Paris, 75005, France \\ ${ }^{6}$ Université Pierre et Marie Curie, Paris, 75231, France \\ ${ }^{7}$ Qatar Environment and Energy Research Institute (QEERI), PO Box 5825, Doha, Qatar \\ ${ }^{8}$ Hamad bin Khalifa University (HBKU), PO Box 5825, Doha, Qatar \\ *E-mail Address: h.ennaceri@ aui.ma
}

\begin{abstract}
.
This study presents an experimental approach for fabricating super-hydrophobic coatings based on a dual roughness structure composed of zinc oxide nanorod arrays coated with a sputtered zinc oxide nano-layer. The $\mathrm{ZnO}$ nanorod arrays were grown by mean of low-temperature electrochemical deposition technique $\left(75^{\circ} \mathrm{C}\right)$ on FTO substrates with pre-sputtered $\mathrm{ZnO}$ seed layer of $30 \mathrm{~nm}$ thickness. The $\mathrm{ZnO}$ nanorods show a (002) orientation along the c-axis, and have a hexagonal structure, with an average length of $710 \mathrm{~nm}$, and average width of $156 \mathrm{~nm}$. On the other hand, the crystallite size of the top-coating sputtered $\mathrm{ZnO}$ layer is of $30 \mathrm{~nm}$. The as-deposited $\mathrm{ZnO}$ nanorod arrays exhibited a hydrophobic behavior, with a surface water contact angle of $108^{\circ}$, whereas the dual-scale roughness $\mathrm{ZnO}$ nanorods coated with sputtered $\mathrm{ZnO}$ exhibited a superhydrophobic behavior, with a surface water contact angle of $157^{\circ}$ and high water droplet adhesion. The photo-catalytic degradation of methylene blue in the presence of both the single roughness $\mathrm{ZnO}$ nanorod arrays, and dual roughness structured $\mathrm{ZnO}$. The $\mathrm{ZnO}$ nanorod arrays showed good activity, with a degradation efficiency of $50 \%$ and a degradation constant of $\left(k=0.00225 \mathrm{~min}^{-1}\right)$ after 5 hours of UV illumination. On the other hand, the $\mathrm{ZnO}$ dual roughness structure prepared by sputtered $\mathrm{ZnO}$ on top of the $\mathrm{ZnO}$ nanorod arrays showed minimal activity, with a degradation efficiency of $16 \%$ and a degradation constant of $\left(\mathrm{k}=0.000586 \mathrm{~min}^{-1}\right)$ after 5 hours of UV exposure. The double structured films exhibited high sensitivity to UV light, with a UV-induced switching behavior from super-hydrophobic to super-hydrophilic after only 30 minutes of UV exposure.
\end{abstract}

Key Words: Super-hydrophobic, water contact angle, zinc oxide, nanorod arrays, rose petal effect, photo-catalysis. 


\section{Highlights}

- Hydrophobic $\mathrm{ZnO}$ nanorod arrays with high water-adhesion are achieved.

- Sputtered $\mathrm{ZnO}$ top-coating is used to reach super-hydrophobicity.

- Switchable wettability for $\mathrm{ZnO}$ single and dual roughness films under UV exposure.

- Strong pinning to the surface, similar to the rose-petal effect.

- The higher WCA is responsible for the decrease in the photo-catalysis activity. 


\section{Introduction and Background}

Zinc oxide is an important n-type semiconducting material due to its wide band gap (3.37 eV at room temperature) [1] and large exciton binding energy (60 meV) [2]. $\mathrm{ZnO}$ is emerging as an efficient photo-catalyst due to its high surface reactivity, reaction and mineralization rates [3]. Because of the major importance of surface area and surface defects in the photo-catalytic activity of metal oxides, one dimensional structures such as nanowires or nanorods represent ideal candidate structures for photo-catalytic applications due to their large surface-to-volume ratio compared to thin films [4].

There is a big interest in growing $\mathrm{ZnO}$ nanorods for their potential use in different applications such as dye sensitized solar cells [5, 6], anti-reflective coatings (ARC) [7], chalcopyrite solar cells [8, 9], light-emitting diodes [10], photo-catalysts [11-13], and gas sensing devices [14, 15]. Different processes have been reported to fabricate zinc oxide nanorods, such as physical vapor deposition [16, 17], chemical vapor deposition [18], wet chemical deposition [19, 20], ink-jet printing and hydrothermal processes [21, 22], surfactant assisted hydrothermal methods [23], vapor phase transport [24, 25], and pulsed laser deposition [26].

Electrochemical and chemical bath depositions conducted at low temperatures [27, 28] represent an easy, fast preparation and non-toxic process to prepare zinc oxide nanorod arrays. Moreover, they can be up-scaled for industrial applications.

Zinc oxide is intrinsically hydrophilic, which is due to the presence of hydroxyl groups on its surface [29, 30]. However, $\mathrm{ZnO}$ can be used to prepare hydrophobic surfaces by creating hierarchical structures and roughening the surfaces [31, 32]. There exist two types of superhydrophobic surfaces, low and high water-adhesion super-hydrophobicity [33-35]. The first type is inspired from the lotus plant, and is observed with water contact angles exceeding $150^{\circ}$, and very low sliding angles (not exceeding $10^{\circ}$ ) [36]. On the other hand, high water-adhesion superhydrophobicity is inspired from the rose-petal effect or the gecko's feet [37-39]. This type of surfaces is characterized by high water contact angle (exceeding $150^{\circ}$ ) and high water adhesion demonstrated by the firm pinning behavior of the water droplet to the surface at any sliding angle [40]. 
The wettability of surfaces play an important role in different applications, and the creation of low water-adhesion super-hydrophobic coatings have attracted special interest due to their potential application for ultra-dry surfaces, self-cleaning and anti-fogging coatings. On the other hand, the high adhesive rose-petal super-hydrophobicity can be used in applications such as liquid transportation [41, 42] and single molecule spectroscopy [43].

The surface wettability of a chemically homogeneous smooth surface depends on the chemical surface composition. Theoretically, the contact angle $(\theta)$ of a droplet deposited on a perfectly flat surface can be calculated using Young's equation [44], Where $\left(\gamma_{S V}\right)$ is the solid-vapor, $\left(\gamma_{S L}\right)$ is the solid-liquid and $\left(\gamma_{L V}\right)$ is the liquid-vapor interfacial energies:

$$
\cos \theta_{\text {Smooth }}=\frac{\gamma_{S V}-\gamma_{S L}}{\gamma_{L V}}
$$

On the other hand, the effect of surface roughness on the wettability was first discussed by Wenzel in 1936 [45] and then by Cassie and Baxter in 1944 [46]. Wenzel suggested that the increase in the surface roughness increases the effective surface area, which would make a water droplet spread more on rough hydrophilic surfaces and develop more solid-liquid contact. In the same way, the increase in the effective surface area would make a water droplet spread less on a rough hydrophobic surface to decrease the contact area to solid. The key assumption of this model is the fact that the water droplet makes complete contact with the solid surface by penetrating into the asperities of the surface, which is called Wenzel state, which is described by Eq. (2), where $\left(\theta_{\text {rough }}\right)$ is the apparent contact angle on a rough surface, $r$ is the roughness factor and $(\theta)$ is the intrinsic contact angle described by Young's equation:

$$
\cos \theta_{\text {rough }}=r \cos \theta_{\text {Smooth }}
$$

However, as the surface hydrophobicity increases as a result of a surface roughness increase, it becomes improbable that the water droplet would have a complete contact with the surface by completely following the surface topography of a hydrophobic surface. As a result, air may be trapped between the water droplet and the surface texture, which makes the water in contact with a composite surface of solid and air and forms fakir droplets, which is described by the CassieBaxter equation, where $\left(\theta_{C}\right)$ is the apparent contact angle, $\left(\phi_{S}\right)$ and $\left(\phi_{V}\right)$ are the fractions of solid 
and air in contact with the water droplet $\left(\phi_{S}+\phi_{V}=1\right)$, and $\left(\theta_{L V}\right)$ is the contact angle of water in $\operatorname{air}\left(\theta_{L V}=180^{\circ}\right)$ :

$$
\cos \theta_{C}=\phi_{S} \cos \theta_{\text {Smooth }}+\phi_{V} \cos \theta_{L V}=\phi_{S} \cos \theta_{\text {Smooth }}-\left(1-\phi_{S}\right)
$$

In the Cassie state, a decrease in the solid fraction contacting the water droplet $\left(\phi_{S}\right)$ ) would increase the apparent super-hydrophobicity of the surface, consequently, when more air is trapped in the surface asperities results in an increase in the apparent surface hydrophobicity.

In contrast with the Wenzel and Cassie-Baxter regimes, the high adhesion rose-petal effect occurs with a special wetting state referred to as the Cassie-impregnating regime [39] in which the water droplet penetrates into the microstructure but only partially penetrates into the nanostructures, causing high sliding angles, and therefore high water adhesion.

Previous research focused on selecting $\mathrm{ZnO}$ micro-rods to create a fakir effect, by making a composite surface that consists of both $\mathrm{ZnO}$ and air, and minimizing the contact between the water droplet and the surface $[47,48]$ in order to achieve low water-adhesion super-hydrophobicity. Other research focused on using $\mathrm{ZnO}$ nanorods followed by surface modification in order to create surface roughness-induced super-hydrophobicity [49, 50], the work of Xue et al. [51] consisted on fabricating hydrophobic $\mathrm{ZnO}$ nanorods by electrodeposition, followed by a top coating of $\mathrm{Cu}_{2} \mathrm{O}$ on the $\mathrm{ZnO}$ nanorod arrays. The $\mathrm{Cu}_{2} \mathrm{O}$-coated $\mathrm{ZnO}$ nanorod arrays exhibited a super-hydrophobic behavior, with a water contact angle reaching $166^{\circ}$ and a sliding angle of $2^{\circ}$. Other research have been dedicated to study the effect of sticky super-hydrophobicity, or super-hydrophobicity with high sliding angles, due to high water adhesion using $\mathrm{ZnO}$ nanorods [34, 49, 52].

The purpose of this work is to study the surface morphology, structure, wetting properties and switching behavior under UV light exposure, as well as the photo-catalysis ability of both hydrophobic single roughness surface, fabricated with $\mathrm{ZnO}$ nanorod arrays only, and superhydrophobic dual roughness surface fabricated with $\mathrm{ZnO}$ nanorod arrays top coated with a layer of sputtered $\mathrm{ZnO}$. 


\section{Experimental Details}

\subsection{Preparation of $\mathrm{ZnO}$ Nano rods}

In this work, $\mathrm{ZnO}$ nanorod arrays (NRA) have been prepared by mean of electrochemical deposition. The $\mathrm{ZnO}$ NRA are grown on $5 \times 5 \mathrm{~cm}^{2}$ fluorine doped tin oxide coated glass (FTO) substrates of $7 \Omega /$ sq from Pilkington. Before the deposition, the FTO substrates were cleaned by successively rinsed ultrasonically in acetone, ethanol and ultra-pure $\mathrm{H}_{2} \mathrm{O}$, after the substrates were cleaned, they were subsequently blown with Nitrogen to dry.

The ZnO NRA are electrochemically grown on top of the FTO substrate, with a pre-deposited 30 $\mathrm{nm}$ intrinsic $\mathrm{ZnO}$ seed layer (SL) is pre-deposited by mean of sputtering as previously published by Tang et al. [53]. Previous work by Elias et al. [54] demonstrates that electrodeposited $\mathrm{ZnO}$ nanowire arrays on $\mathrm{ZnO}$ buffer layers showed increased nanowire density, compared to nanowire arrays deposited directly on the substrate. Therefore, the intrinsic $\mathrm{ZnO}$ seed layer is used to control the number of nucleation sites for $\mathrm{ZnO} \mathrm{NR}$ growth.

The $\mathrm{ZnO}$ nanorod arrays prepared in this work were grown on the FTO substrates with the predeposited $30 \mathrm{~nm}$ i-ZnO seed layer from a magnetically stirred aqueous solution of $5 \mathrm{mM}$ of zinc nitrate hexahydrate $\left[\mathrm{Zn}\left(\mathrm{NO}_{3}\right)_{2} \cdot 6 \mathrm{H}_{2} \mathrm{O}\right]$ and $5 \mathrm{mM}$ of Ammonium nitrate $\left[\mathrm{NH}_{4} \mathrm{NO}_{3}\right]$ kept at a low temperature of $75^{\circ} \mathrm{C}$ following the standard conditions presented by Ludwig et al. [55].

The experimental set up is comprised of a three electrode system, with the substrate as the working electrode, a Platinum sheet as the counter electrode, and a Platinum wire as the pseudo reference electrode (constant potential during the deposition at $0.338 \mathrm{~V}$ vs. $\mathrm{Ag} / \mathrm{AgCl}$ ). The deposition time takes place for 2000 seconds at a constant potential of $1.4 \mathrm{~V}$ versus $\mathrm{Pt}$.

The $\mathrm{ZnO}$ nanorod arrays are formed by the $\mathrm{NO}^{3-}$ precursors following the reaction mechanism suggested by Izaki et al. [56-58]:

$$
\begin{gathered}
\mathrm{Zn}\left(\mathrm{NO}_{3}\right)_{2} \rightarrow \mathrm{Zn}^{2+}+2 \mathrm{NO}_{3}^{-} \\
\mathrm{NO}_{3}^{-}+2 e^{-}+\mathrm{H}_{2} \mathrm{O} \rightarrow 2 \mathrm{OH}^{-}+\mathrm{NO}_{2}^{-} \\
\mathrm{Zn}^{2+}+2 \mathrm{OH}^{-} \rightarrow \mathrm{Zn}(\mathrm{OH})_{2} \\
\mathrm{Zn}(\mathrm{OH})_{2} \rightarrow \mathrm{ZnO}+\mathrm{H}_{2} \mathrm{O}
\end{gathered}
$$


After the deposition, the prepared substrates were ultrasonically cleaned in Ethanol for 3 minutes, followed by pure water for 3 minutes, and then dried with Nitrogen to remove residual salts. The morphology of the ZnO NRA was observed using scanning electron microscopy (SEM).

\subsection{Preparation of $\mathrm{ZnO}$ thin film using reactive magnetron sputtering}

Intrinsic $\mathrm{ZnO}$ thin films were grown by mean of radio frequency magnetron sputtering on top of the $\mathrm{ZnO}$ nanorod arrays at a chamber temperature of $275^{\circ} \mathrm{C}$. The films were grown in pure Argon atmosphere, with a working pressure of $\mathrm{e}^{-5} \mu \mathrm{bar}$, a power of $1.5 \mathrm{~kW}$ and a target-to-substrate distance of nearly $70 \mathrm{~mm}$. The average deposition time for the intrinsic $\mathrm{ZnO}$ thin films was 12 minutes.

\subsection{Photo-catalysis Test}

The photo-catalysis of the $\mathrm{ZnO}$ nanorod arrays as well as the $\mathrm{ZnO}$ nanorods covered with sputtered $\mathrm{ZnO}$ (dual roughness) was evaluated using methylene blue hydrate $\left(\mathrm{MB}, \mathrm{C}_{16} \mathrm{H}_{18} \mathrm{CIN}_{3} \mathrm{~S} . \mathrm{xH}_{2} \mathrm{O}\right.$, Fluka Analytical). The photo-degradation test was conducted using $20 \mathrm{ml}$ of methylene blue solution with an initial concentration of $0.01 \mathrm{mMol} / \mathrm{l}$ in the presence of FTO substrates $\left(25^{*} 25^{*} 2\right.$ $\mathrm{mm}$ ) coated with $\mathrm{ZnO}$ nanorod arrays and $\mathrm{ZnO}$ double structured layers. The $\mathrm{pH}$ value of the prepared MB solution ( $\mathrm{pH}=6.8$ ) was measured with an SP70P/VWR pH measurement instrument.

The concentration of the MB solution was calculated from the UV-Vis measurements of the absorption spectrum using an Avantes Ava Light-DH-S-BAL spectrophotometer. $700 \mu 1$ of the solution was withdrawn each time interval and its optical absorption was measured.

In order to ensure that the dye degradation is due to the UV light exposure, and not on the absorption of the dye by the surface of the $\mathrm{ZnO}$ films, a dark test was first conducted by adding the $\mathrm{ZnO}$ single roughness and dual roughness films to the $\mathrm{MB}$ dye solution, and storing in the dark for 1 hour. The optical absorption of the dye after the dark test was taken as a baseline for the photo-catalysis test under UV illumination.

The photo-degradation test was conducted during a time interval ranging from 1 hour to 5 hours, the irradiation was provided by $2 * 15 \mathrm{~W}$ UV lamps (NU-15 KL) with a radiation power of 2 $\mathrm{mW} / \mathrm{cm}^{2}$ and major emission at $365 \mathrm{~nm}$. The MB solution was magnetically stirred during the experiment, with a rotation of $115 \mathrm{rpm}$. 
The degradation of the MB dye was calculted from the absorption intensity reduction at wavelength $\left(\lambda_{\max }=665 \mathrm{~nm}\right)$. The degradation efficiency (DE) was calculated using the Eq. (8):

$$
D E(\%)=\frac{I_{0}-I}{I_{0}} * 100=\frac{C_{0}-C}{C_{0}} * 100
$$

Where:

- $I_{0}$ : Initial absorption intensity of the MB dye at $\lambda_{\max }=665 \mathrm{~nm}$

- I: Absorption intensity of the MB dye at $\lambda_{\max }=665 \mathrm{~nm}$ after photo-irradiation

- $C_{0}$ : Initial concentration of the dye $\left(C_{0}=0.01 \mathrm{mMol} / \mathrm{l}\right)$

- $C$ : Concentration of the dye after photo-irradiation

In order to calculate the degradation efficiency, a knowledge of the concentration of the MB dye after photo-irradiation is needed. For this reason, the MB calibration curve was developed by preparing different MB solutions with different concentrations $(0.001 \mathrm{mMol} / \mathrm{l}, 0.002 \mathrm{mMol} / \mathrm{l}$, $0.003 \mathrm{mMol} / \mathrm{l}, 0.004 \mathrm{mMol} / \mathrm{l}, 0.005 \mathrm{mMol} / \mathrm{l}, 0.006 \mathrm{mMol} / \mathrm{l}, 0.007 \mathrm{mMol} / \mathrm{l}, 0.008 \mathrm{mMol} / \mathrm{l}, 0.009$ $\mathrm{mMol} / \mathrm{l}$ and $0.01 \mathrm{mMol} / \mathrm{l})$, and their respective absorption spectra were measured.

\subsection{Film Characterization}

The crystalline structure of $\mathrm{ZnO}$ layers was determined by an X-ray diffractometer (Siemens D5000 XRD unit) in $2 \theta$ range from $20^{\circ}$ to $80^{\circ}$ by $0.07^{\circ} \mathrm{s}^{-1}$ increasing steps operating at $40 \mathrm{KV}$ accelerating voltage and $40 \mathrm{~mA}$ current using $\mathrm{CuK} \alpha$ radiation source with $\lambda=1.5406 \AA$.

The morphological investigations of the prepared films were achieved with a high-resolution Ultra 55 Zeiss FEG scanning electron microscope (FEGSEM) operating at an acceleration voltage of 10 $\mathrm{kV}$.

The film thickness was determined using a Dektak8stylus profiler (stylus diamond tip radius = $12.5 \mu \mathrm{m}$, vertical range from $5 \mathrm{~nm}$ to $1 \mathrm{~mm}$, stylus tracking force range from 0.03 to $15 \mathrm{mg}$ ).

The optical properties of the prepared $\mathrm{ZnO}$ films were investigated by measuring the transmittance ad reflectance using a UV-VIS-NIR Perkin Elmer Lambda 950 spectrophotometer, equipped with a $150 \mathrm{~mm}$ integrating sphere and a wavelength range up to $3300 \mathrm{~nm}$ (wavelength range of $200 \mathrm{~nm}$ to $2500 \mathrm{~nm}$ with a step width of $2 \mathrm{~nm}$ ). 
The wettability of the samples was evaluated using an OCA 15 plus contact angle system (microsyringe with a droplet size of $5 \mu \mathrm{l}$ ). The water drops' images were snapped 5 seconds after the deposition of the drop on the samples.

\section{Results and Discussion}

\subsection{X-Ray Diffraction Pattern}

As depicted in Figure 1, the XRD pattern shows the formation of the $\mathrm{ZnO}$ wurtzite hexagonal phase, which is dominated by the (002) crystallographic plane, confirming the strong (002) textures. For the $\mathrm{ZnO}$ nanorod array top coated with sputtered $\mathrm{ZnO}$ (deposited on FTO substrate), the diffraction peaks located at $2 \theta=31.7^{\circ}, 34.4^{\circ}, 36.2^{\circ}, 47.5^{\circ}, 56.6^{\circ}, 62.8^{\circ}, 67.9^{\circ}, 69.09^{\circ}$ and $72.5^{\circ}$, which corresponds to the (100), (002), (101), (102), (110), (103), (112), (201) and (004) planes of the hexagonal wurtzite phase of Zinc Oxide. On the other hand, for the sputtered $\mathrm{ZnO}$ layer with a thickness of $100 \mathrm{~nm}$ deposited on a glass substrate, the diffraction peaks located at $2 \theta$ $=34.4^{\circ}, 36.2^{\circ}, 47.5^{\circ}$ and $62.8^{\circ}$, corresponding to the (002), (101), (102) and (103) crystallographic planes, which is in accordance with the Joint Committee on Powder Diffraction Standards (JCPDS (JCPDS 36-1451).
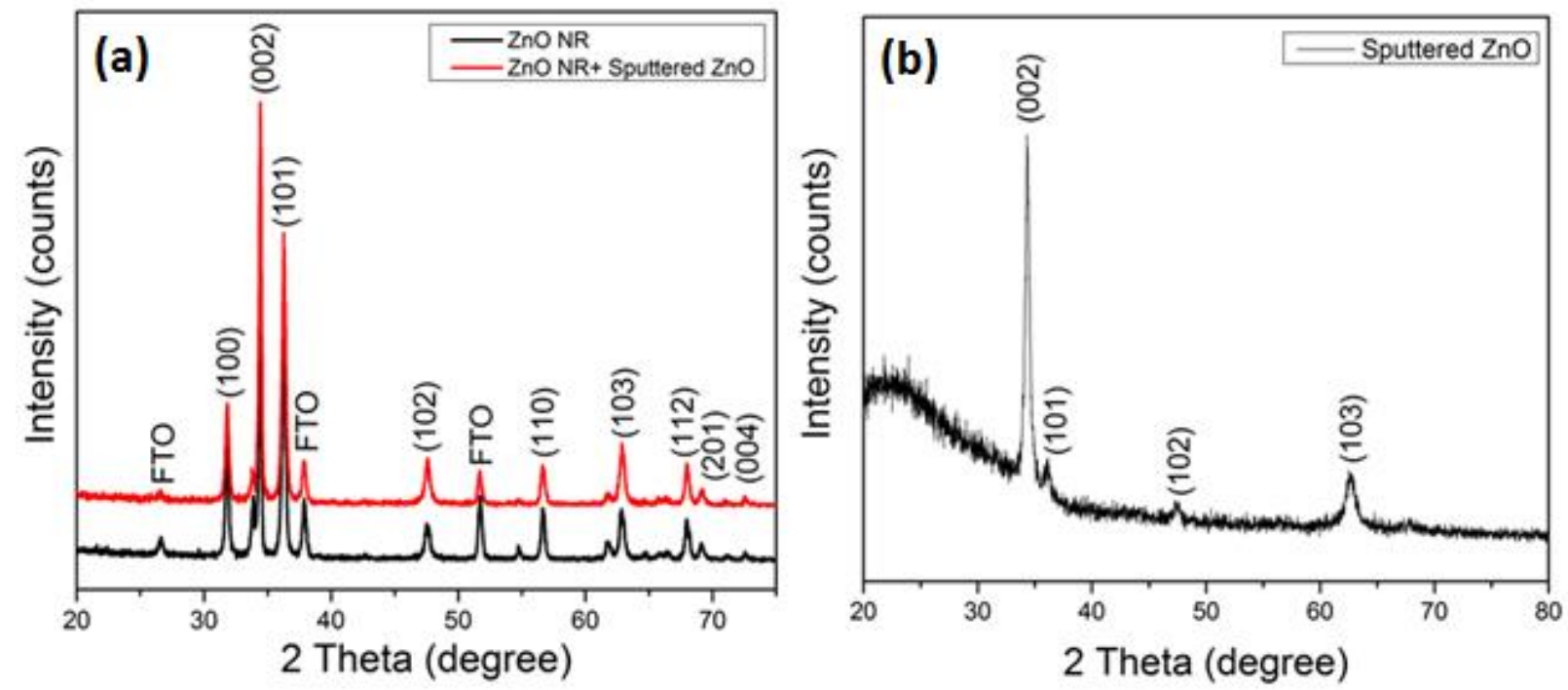

Figure 1. X-Ray Diffraction Pattern for (a) single roughness ZnO NRA and dual roughness ZnO NRA coated with sputtered $\mathrm{ZnO}$ (b) Sputtered $\mathrm{ZnO}$ layer with $100 \mathrm{~nm}$ thickness deposited on glass

The crystallite size was estimated from the XRD data using the Debye-Scherrer equation [59, 60]: 


$$
d_{R X}=\frac{K \lambda}{\beta(2 \theta) \cos \theta}
$$

Where $d_{R X}$ is the crystallite size, $\mathrm{K}$ is the Scherrer correlation constant to account for particle size $(\mathrm{K}=0.9), \lambda=1.54 \AA$ is the wavelength $(C u K \alpha), \beta(2 \theta)$ is the Full Width Half Maximum (FWHM) of the most intense peak (in radians) and $\theta$ is the angle between the incident ray and the scattering planes (Bragg angle). The value of $\mathrm{K}$ be taken as 0.89 or 0.9 for Full Width Half Maximum (FWHM) of spherical crystals with cubic symmetry. Discussion of the values of K are available in the work of Langford et al. (1987) [61].

The estimated crystallite size of sputtered intrinsic $\mathrm{ZnO}$ from the XRD dominating peak corresponding to the crystallographic plane (002) is of $30 \mathrm{~nm}$.

\subsection{Optical Measurements}

The optical transmittance of the deposited $\mathrm{ZnO}$ NRA, and $\mathrm{ZnO}$ NRA coated with sputtered $\mathrm{ZnO}$ was measured, showing that the layers were transparent in the visible range, with approximately $60 \%$ transmittance for ZnO Nanorod arrays deposited on FTO substrates (Fig.2 (b)), with a slight decrease after the deposition of the sputtered $\mathrm{ZnO}$ top coating layer.
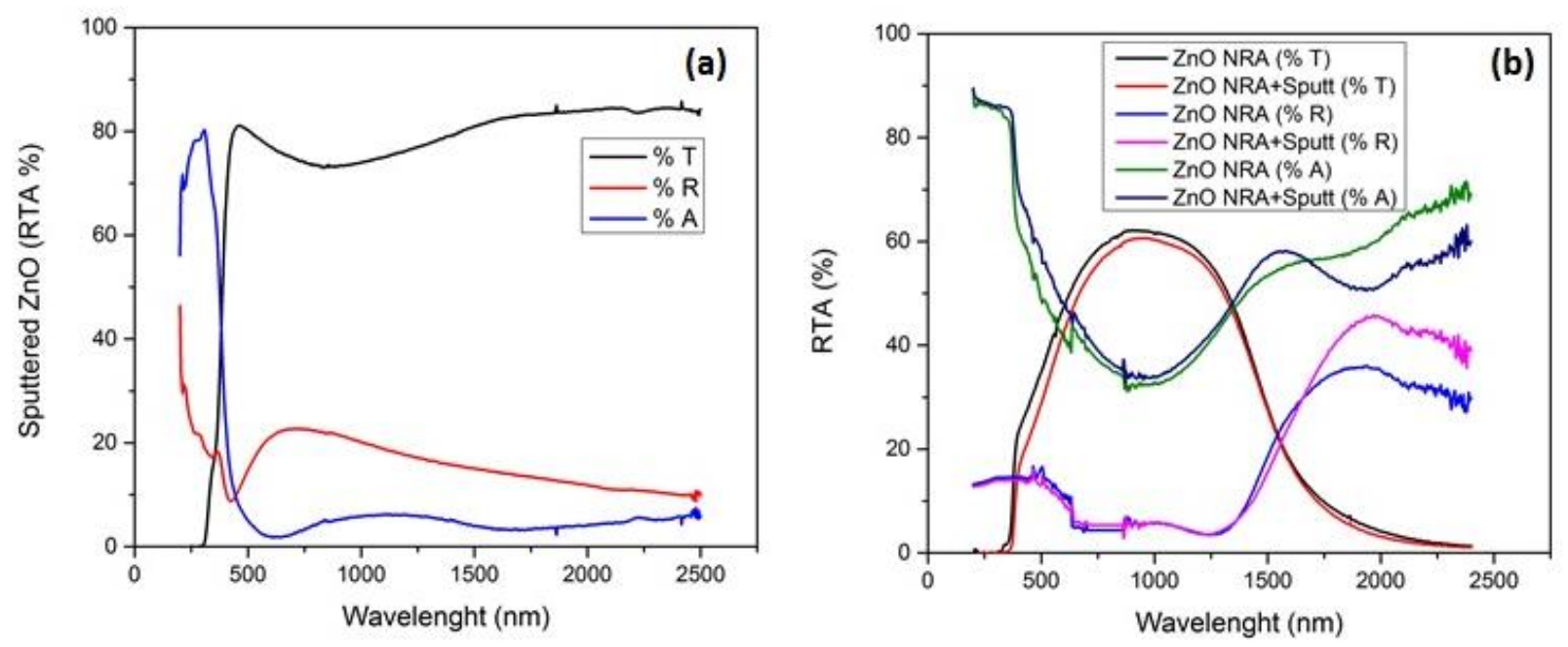

Figure 2. Optical measurements of (a) the sputtered $\mathrm{ZnO}$ deposited on glass (b) the as-grown $\mathrm{ZnO}$ NRA and the $\mathrm{ZnO}$ NRA coated with sputtered $\mathrm{ZnO}$ deposited on FTO 


\subsection{Surface Morphology and Wettability}

The grown $\mathrm{ZnO}$ nanorods have a hexagonal structure (Fig. 3), with an average length of $710 \mathrm{~nm}$, and an average width (diameter) of $156 \mathrm{~nm}$ (Fig. 5 (a)).

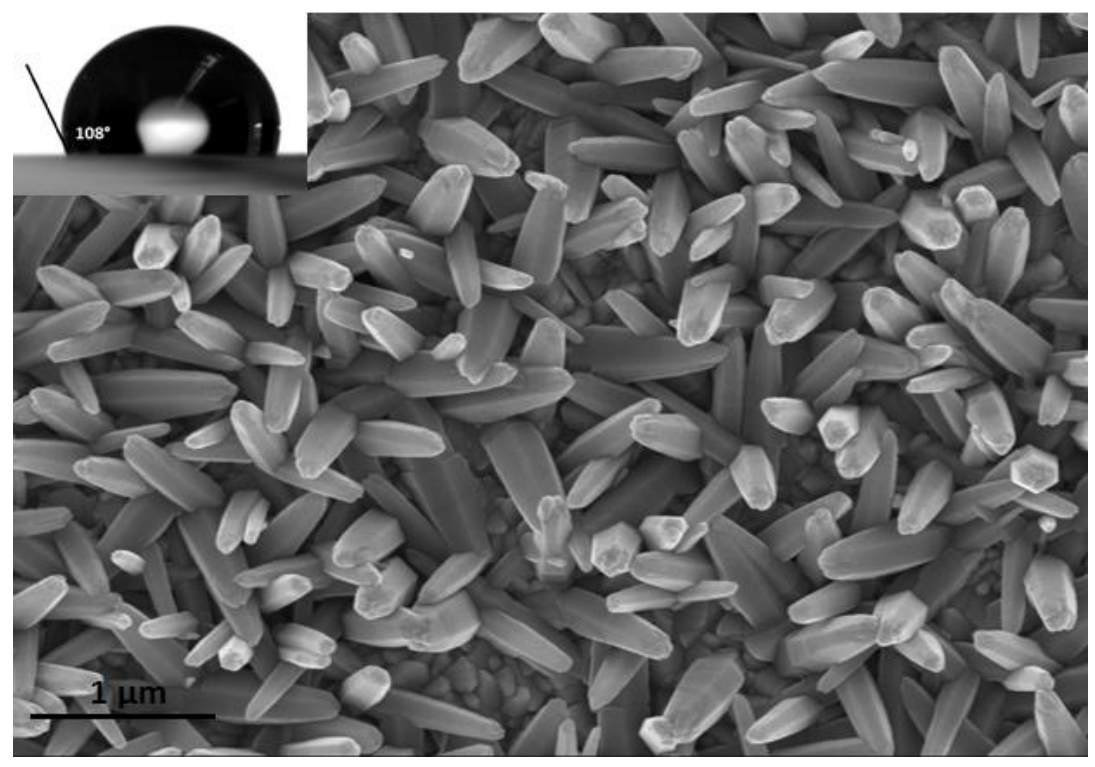

Figure 3. Scanning electron micrographs of the grown ZnO NRA (inset: water contact angle measurement on the single roughness $\mathrm{ZnO}$ nanorods)

The sputtered $\mathrm{ZnO}$ layer is shown in Figure 4. The grain size of sputtered $\mathrm{ZnO}$ film with a thickness of $100 \mathrm{~nm}$ deposited on silver-coated glass is $152 \mathrm{~nm}$ (Fig.4 (a)). The same ZnO sputtered layer has been deposited on top of FTO substrates, showing a crystallite size is of $30 \mathrm{~nm}$ (Fig.4 (b)), this result confirms the calculations conducted from the XRD pattern using the DebyeScherrer equation. 


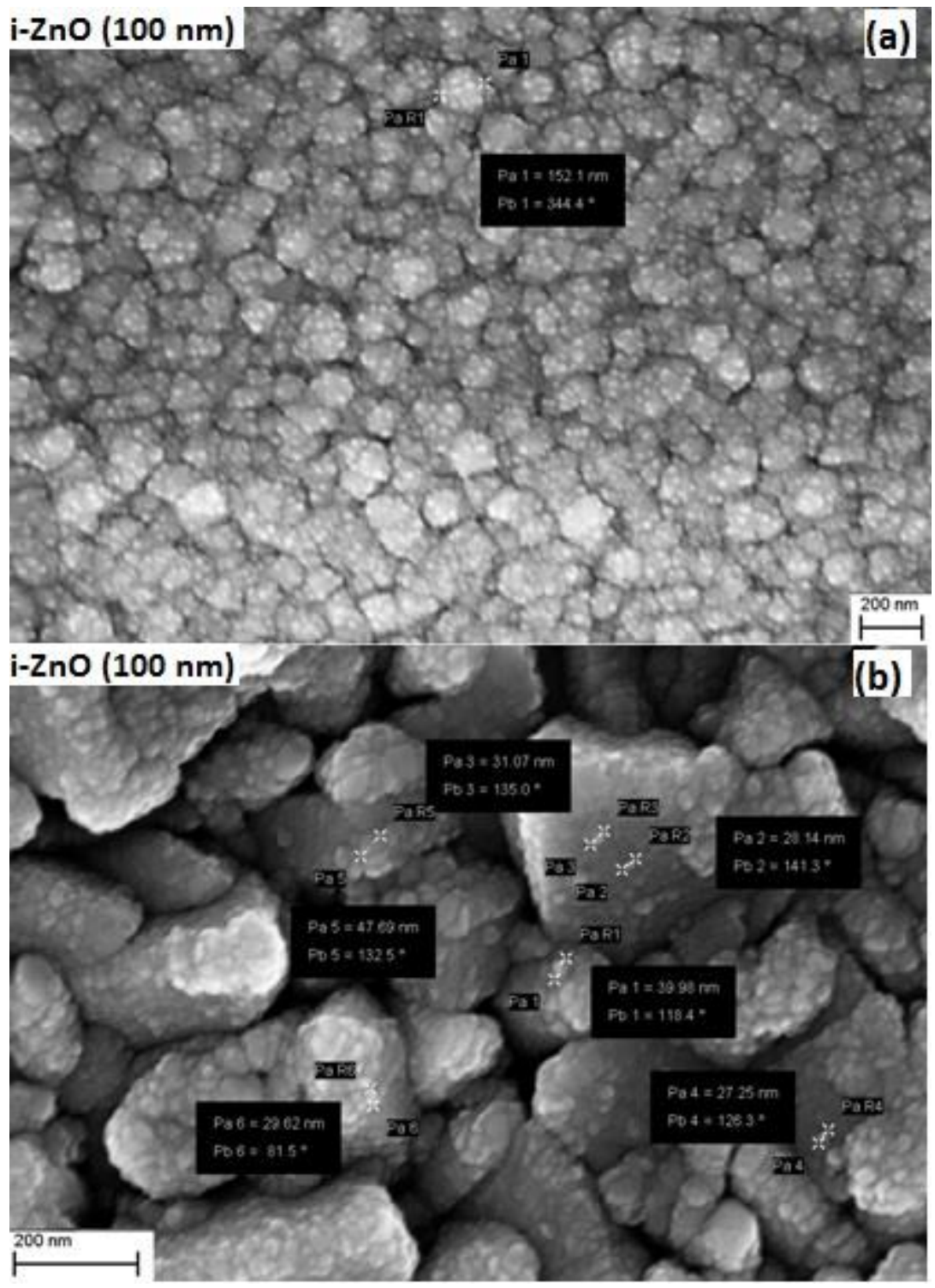

Figure 4. SEM of Sputtered ZnO (a) on Silver-coated glass substrate (b) on FTO substrate

The as-deposited $\mathrm{ZnO}$ Nano rods layers exhibited a hydrophobic behavior, with a surface water contact angle of $108^{\circ}$. On the other hand, and as illustrated in Figure 5, the water contact angle measured on the surface of the single roughness $\mathrm{ZnO}$ nanorod arrays $\left(108^{\circ}\right)$ increases to $157^{\circ}$ by the creation of a double structured $\mathrm{ZnO}$ layer, exhibiting a super-hydrophobic behavior. 


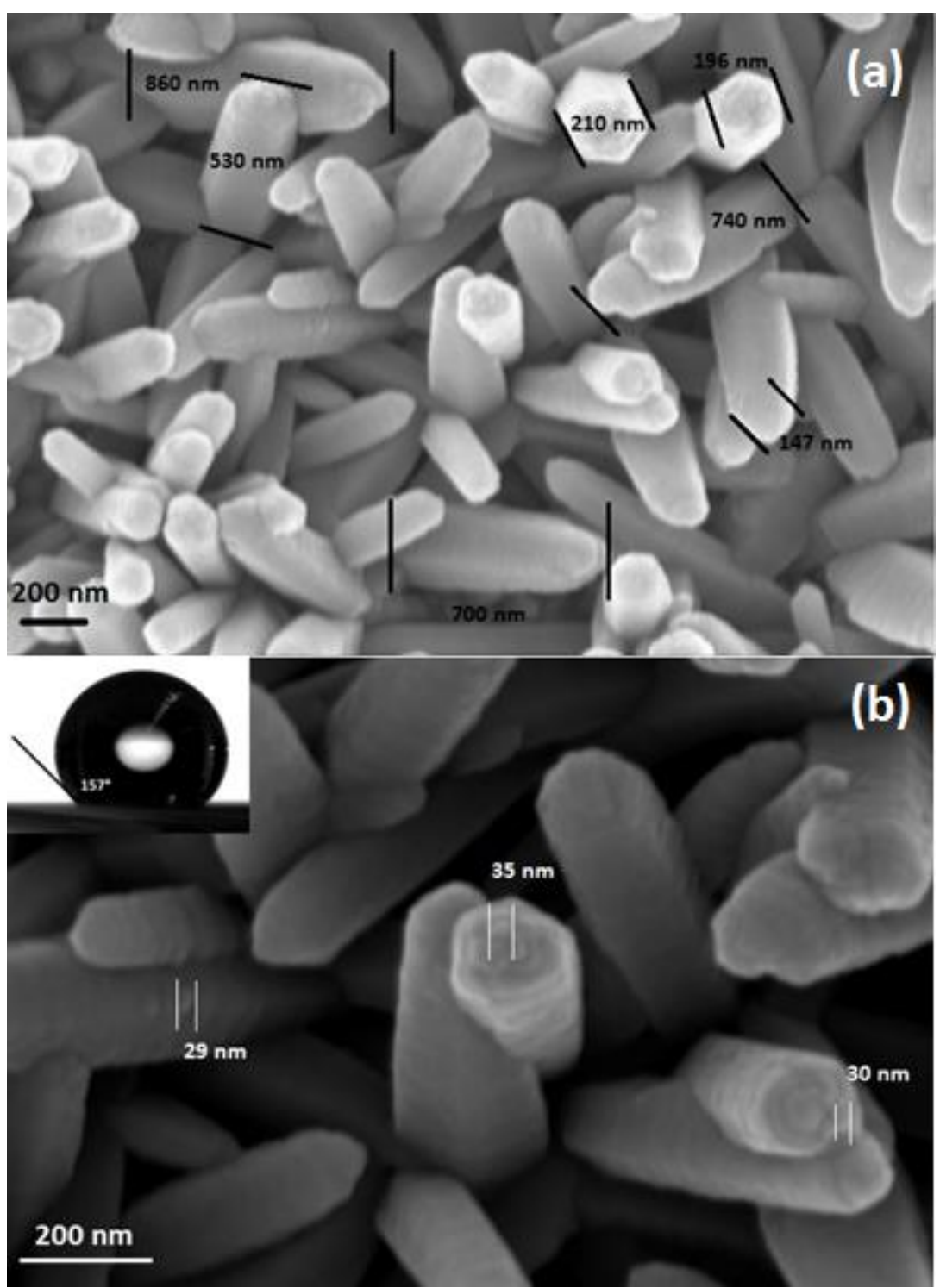

Figure 5. Scanning electron micrographs of the dual-roughness structured $\mathrm{ZnO}$ film (a) nanorod length and diameter (b) nanostructures on top of the $\mathrm{ZnO}$ nanorods (inset: water contact angle measurement on the double structured $\mathrm{ZnO}$ layer)

In order to evaluate the wetting behavior of surfaces, a knowledge of the roll-off angle is of major importance. In fact, the Wenzel state is dominant for surfaces with sliding angle higher than $20^{\circ}$ whereas the Cassie-Baxter state is dominant for surfaces with sliding angles lower than $10^{\circ}$. In this work, the hydrophobicity of the $\mathrm{ZnO}$ nanorod arrays was improved from $108^{\circ}$ to $157^{\circ}$ by creating a dual-roughness structure as depicted in Figure 5(b). The wettability measurements show that both the prepared single-scale roughness $\mathrm{ZnO}$ nanorod arrays as well as the dual-scale ZnO NRA coated with sputtered $\mathrm{ZnO}$ are highly adhesive, with a very firm pinning behavior. In fact, the water droplet does not slide even with a vertical sliding angle, and even when the substrate is 
turned upside down, which is very similar to the rose-petal effect, resulting from the Cassieimpregnating sticky-type super-hydrophobic state. This result is in accordance with previous research, which shows that a rose-petal effect can be obtained by both single-scale and dual-scale roughness [62].

\subsection{Wetting Behavior under UV Illumination}

The wettability of both samples was also studied under UV illumination. Previous research were dedicated to investigate the $\mathrm{ZnO}$ switching behavior from hydrophobicity to under $\mathrm{UV}$ light exposition [63, 64]. In fact, the illumination of ZnO layers with UV light with photon energy equal or higher than the bang gap of $\mathrm{ZnO}(3.37 \mathrm{eV})$ generates electron-hole pairs in the surface of the $\mathrm{ZnO}$ layers. The electrons $\left(e^{-}\right)$in the valence band are excited to the conduction band, and the same number of holes $\left(h^{+}\right)$are generated in the valence band. The process that leads to the surface composition change is explained as follows:

$$
\begin{gathered}
\mathrm{ZnO}+2 \mathrm{hv} \rightarrow 2 h^{+}+2 e^{-} \\
\left.\mathrm{O}^{2-}+h^{+} \rightarrow \mathrm{O}^{1-} \text { (Surface trapped hole }\right) \\
\mathrm{Zn}^{2+}+e^{-} \rightarrow \mathrm{Zn}_{\mathrm{S}}^{+} \text {(Surface trapped electron) } \\
\mathrm{O}^{1-}+h^{+} \rightarrow \frac{1}{2} \mathrm{O}_{2}+V_{O} \text { (Oxygen vacancy) }
\end{gathered}
$$

Surface oxygen vacancies $\left(\mathrm{O}^{1-}\right)$ are formed when some of the holes react with lattice oxygen $\left(\mathrm{O}^{2-}\right)$ while defective $\left(\mathrm{Zn}_{\mathrm{S}}^{+}\right)$sites are formed when some of the electrons react with the lattice metal ion $\left(\mathrm{Zn}^{2+}\right)$. When the $\mathrm{ZnO}$ layers are in contact with water, the water molecules may adsorb at the oxygen vacancy $\left(\mathrm{V}_{\mathrm{O}}\right)$ site. The defective sites are kinetically more favorable for hydroxyl groups $\left(\mathrm{OH}^{-}\right)$adsorption than oxygen adsorption. Therefore, it stimulates increased water adsorption at the UV light irradiated $\mathrm{ZnO}$ layers, which results in a hydrophilic behavior of the surface. $\mathrm{H}_{2} \mathrm{O}$ and $\mathrm{O}_{2}$ can both adsorb on these defective sites. The surface trapped electrons $\left(Z_{S}^{+}\right)$ tend to react with oxygen molecules adsorbed on the surface:

$$
\mathrm{Zn}_{\mathrm{s}}+\mathrm{O}_{2} \rightarrow \mathrm{Zn}_{\mathrm{s}}^{2+}+\mathrm{O}_{2}^{-}
$$

Light induced super-hyprophilicity was studied by irradiating both $\mathrm{ZnO}$ films using a Xenon lamp from Müller Elektronik-Optik with a power of $1400 \mathrm{~W}$. After irradiating the samples for 30 
minutes interval, a $5 \mu$ droplet was placed in the irradiated samples, and the water contact angle was measured using the OCA 15 plus contact angle system.

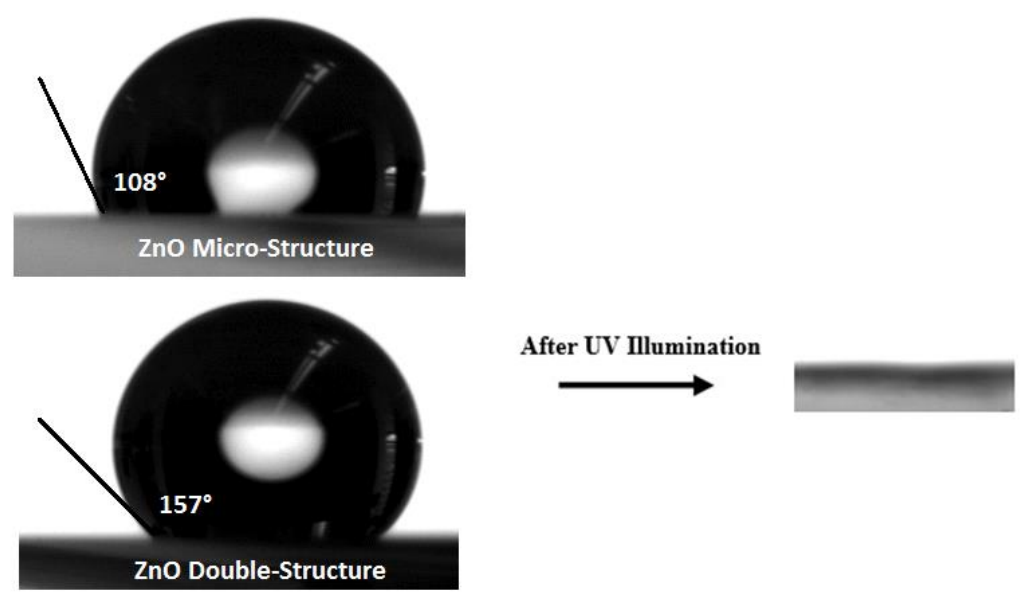

Figure 6. Water contact angle on the single roughness $\mathrm{ZnO}$ NRA and dual roughness structured $\mathrm{ZnO}$ NRA coated with sputtered $\mathrm{ZnO}$ before and after UV illumination.

The water contact angle of both the $\mathrm{ZnO}$ single-scale and dual-scale roughness films decreased significantly after exposure to UV light, exhibiting a super-hydrophilic beavior $\left(\mathrm{WCA}=0^{\circ}\right)$ after 30 minutes of UV exposure. The wetting behavior of both $\mathrm{ZnO}$ layer structures under UV illumination is shown in Figure 6.

\subsection{Photo-catalysis Test}

For the as-grown $\mathrm{ZnO}$ nanorod arrays, the photo-degradation of $\mathrm{MB}$ solution was of $50 \%$ after 5 hours of UV exposition as illustrated in Figure 7 (a): 

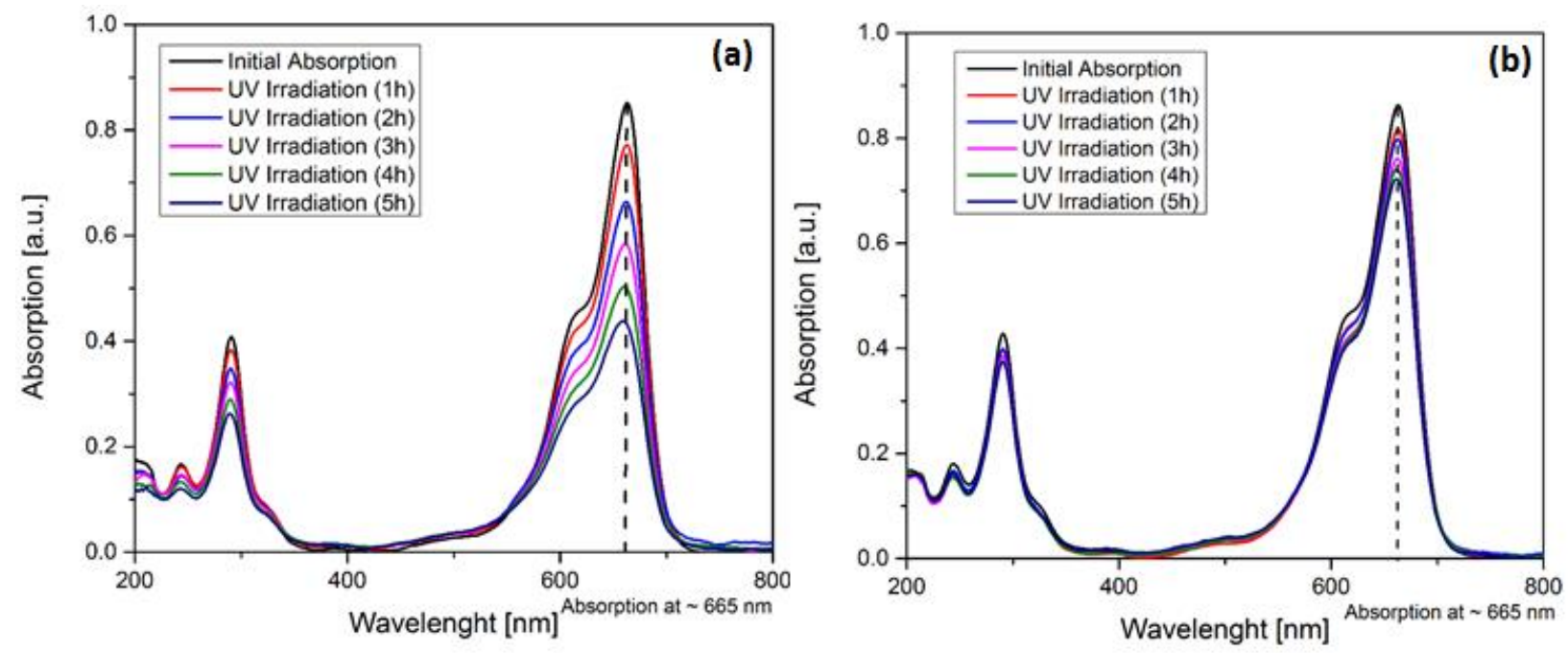

Figure 7. MB degradation by the photo-catalysis of (a) ZnO NRA (b) ZnO NRA top coated with sputtered ZnO

On the other hand, the photo-degradation decreased to $16 \%$, for the $\mathrm{ZnO}$ nanorod arrays covered with a layer of sputtered $\mathrm{ZnO}$ (Fig. 7(b)), which is due to the super-hydrophobic behavior of the layer and the hydrophilic nature of the MB solution.

The results of the photo-catalysis test show that the degradation efficiency of the MB solution with $\mathrm{ZnO}$ nanorod arrays increased with the exposition time to UV light, with $9 \%$ after 1 hour, $22 \%$ after 2 hours, $31 \%$ after 3 hours, $41 \%$ after 4 hours and $50 \%$ after 5 hours. On the other hand, the degradation test was conducted on the double-roughness $\mathrm{ZnO}$ film ( $\mathrm{ZnO} \mathrm{NRA}+$ sputtered $\mathrm{ZnO})$. The results show a lower degradation efficiency of the MB solution. The degradation percent increased with the exposition time to UV light, with 5\% after 1 hour, $7 \%$ after 2 hours, $12 \%$ after 3 hours, $14 \%$ after 4 hours and $16 \%$ after 5 hours.

The photo-degradation of the methylene blue solution can be fitted using Eq. (15), where the degradation constant $\mathrm{k}$ is obtained from the semi-logarithmic plot (plot of $\ln (\mathrm{c} / \mathrm{c} 0)$ versus time) as illustrated in Figure 8 using the following equation [65]:

$$
\ln \left(\frac{C}{C_{0}}\right)=-k t
$$

After 5 hours of UV illumination, the $\mathrm{ZnO}$ nanorod arrays showed good activity, with a degradation efficiency of $50 \%$ and a degradation constant of $\left(\mathrm{k}=0.00225 \mathrm{~min}^{-1}\right)$. On the other hand, the $\mathrm{ZnO}$ dual roughness structure prepared by sputtered $\mathrm{ZnO}$ on top of the $\mathrm{ZnO}$ nanorod 
arrays showed minimal activity, with a degradation efficiency of $16 \%$ and a degradation constant of $\left(\mathrm{k}=0.000586 \mathrm{~min}^{-1}\right)$ after 5 hours of UV exposure.

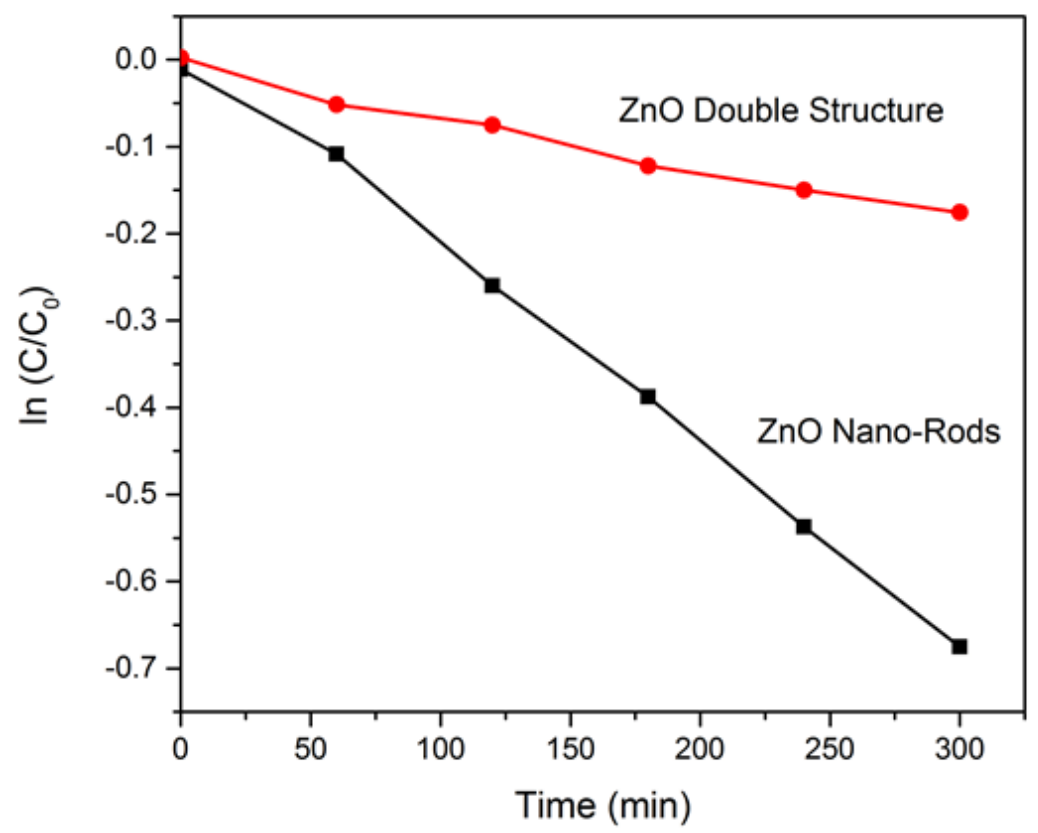

Figure 8. Photo-degradation of the methylene blue solution as a function of $\ln (\mathrm{C} / \mathrm{C} 0)$ versus time of single roughness and dual roughness structured $\mathrm{ZnO}$ films

The decrease in the photo-catalysis degradation of the dual-scale roughness ZnO NRA compared to the as-deposited $\mathrm{ZnO} \mathrm{NRA}$ is due to the increase in the water contact angle $\left(157^{\circ}\right)$, which decreases the contact of the dye with the film, and therefore, leads to a lower photo-catalysis activity.

\section{Conclusion}

It is possible to create a super-hydrophobic coating using $\mathrm{ZnO}$ nanorod array grown by mean of low temperature electrochemical deposition, the creation of a dual-scale roughness needed to achieve super-hydrophobicity is conducted by sputtering an intrinsic $\mathrm{ZnO}$ thin film with a crystallite size of $30 \mathrm{~nm}$ on top of the $\mathrm{ZnO}$ nanorod arrays, which leads to a water contact angle of $157^{\circ}$. The single-scale roughness $\mathrm{ZnO}$ NRA as well as the dual-scale ZnO NRA coated with sputtered $\mathrm{ZnO}$ showed very high water adhesion. In fact, the water droplet was firmly pinned to the film surface and did not slide even with tilt angles up to $180^{\circ}$, which is very similar to the rosepetal effect, known as the Cassie-impregnating super-hydrophobic regime. Moreover, both 
prepared films exhibited high sensitivity to UV light, with a UV-induced switching behavior from super-hydrophobic to super-hydrophilic after only 30 minutes of UV exposure.

\section{Acknowledgments}

This work has been done in the framework of the InnoTherm II project "Nano Coating and Testing: a step towards the improvement of CSP reflectors for less intensive maintenance both in terms of labor and water" supported by IRESEN (Institut de Recharche en Energie Solaire et Energies Nouvelles). The authors would also like to thank the DAAD, for financing the first author of this work. The authors would also like to thank Wibke Riedel from the Helmholtz-Zentrum Berlin für Materialien und Energie, Hahn Meitner Platz 1, 14109 Berlin, Germany for her help with the preparation of the $\mathrm{ZnO}$ nanorod arrays.

\section{References}

[1] V. Srikant, D.R. Clarke, On the optical band gap of zinc oxide, Journal of Applied Physics 83(10) (1998) 5447-5451.

[2] H. Chik, J. Liang, S.G. Cloutier, N. Kouklin, J.M. Xu, Periodic array of uniform ZnO nanorods by second-order self-assembly, Applied Physics Letters 84(17) (2004) 3376-3378.

[3] I. Poulios, D. Makri, X. Prohaska, Photocatalytic treatment of olive milling waste water: oxidation of protocatechuic acid, Global Nest: The International Journal 1 (1999) 55-62.

[4] S. Baruah, R.F. Rafique, J. Dutta, Visible light photocatalysis by tailoring crystal defects in zinc oxide nanostructures, Nano 3(5) (2008) 1-9.

[5] A. C. Cakir, S. Erten-Ela, Comparison between synthesis techniques to obtain ZnO nanorods and its effect on dye sensitized solar cells, Advance Powder Technology 23(5) (2012) 655660.

[6] F. D. Nayeri, M. Kolahdouz, E. Asl-Soleimani, S. Mohajerzadeh, Low temperature carving of $\mathrm{ZnO}$ nanorods into nanotubes for dye-sensitized solar cell application, Journal of Alloys and Compounds 633 (2015) 359-365.

[7] P. S. Kumar, J. Sundaramurthy, X. Zhang, D. Mangalaraj, V. Thavasi, S. Ramakrishna, Superhydrophobic and antireflecting behavior of densely packed and size controlled $\mathrm{ZnO}$ nanorods, Journal of Alloys and Compounds 553 (2013) 375-382. 
[8] J. Chen, H. Ye, L. Ae, Y. Tang, D. Kieven, T. Rissom, J. Neuendorf, M. Ch. Lux-Steiner, Tapered aluminum-doped vertical zinc oxide nanorod arrays as light coupling for solar energy applications, Solar Energy Materials and Solar Cells 95 (201) 1437-1440.

[9] B.-K. Shin, T. Lee, J. Xiong, C. Hwang, G. Noh, J.-H. Cho, J.-M. Myoung, Bottom-up grown $\mathrm{ZnO}$ nanorods for an antireflective moth-eye structure on $\mathrm{CuInGaSe}_{2}$ solar cells, Solar Energy Materials and Solar Cells 95(9) (2011) 2650-2654.

[10] L. Aé, J. Chen, M.Ch. Lux-Steiner, Hybrid flexible vertical nanoscale diodes prepared at low temperature in large area, Nanotechnology 19 (2008) 475201.

[11] G. Wang, D. Chen, H. Zhang, J.Z. Zhang, J. Li, Tunable photocurrent in well-oriented zinc oxide nanorod arrays with enhanced photocatalytic activity, Journal of Physical Chemistry C 112 (2008) 8850-8855.

[12] X. Yang, A. Wolcott, G. Wang, A. Sobo, R.C. Fitzmorris, F. Qian, J.Z. Zhang, Y. Li, Nitrogen-doped $\mathrm{ZnO}$ nanowire arrays for photoelectrochemical water splitting, Nano Letters 9(6) (2009) 2331-2336.

[13] M. Fekete, W. Ludwig, S. Gledhill, J. Chen, A. Patti, L. Spiccia, Al-modified zinc oxide nanorods for photoelectrochemical water oxidation, European Journal of Inorganic Chemistry 4 (2014) 750-759.

[14] B. S. Kang, Y. W. Heo, L. C. Tien, D. P. Norton, F. Ren, B.P. Gila, S .J. Pearton, Hydrogen and ozone gas sensing using multiple ZnO nanorods, Applied Physics A 80 (2005) 1029-1032.

[15] J. X. Wang, X. W. Sun, Y. Yang, H. Huang, Y. C. Lee, O. K. Tan, L. Vayssieres, Hydrothermally grown oriented $\mathrm{ZnO}$ nanorod arrays for gas sensing applications, Nanotechnology 17 (2006) 4995.

[16] Y. C. Kong, D. P. Yu, B. Zhang, W. Fang, S. Q. Feng, Ultraviolet-emitting ZnO nanowires synthesized by a physical vapor deposition approach, Applied Physics Letters 78(4) (2001) 407-409.

[17] R. Teki, T .C. Parker, H. Li, N. Koratkar, T. M. Lu, S. Lee, Low temperature synthesis of single crystalline $\mathrm{ZnO}$ nanorods by oblique angle deposition, Thin Solid Films, 516(15) (2008) 4993-4996.

[18] J.J. Wu, S.C. Liu, Low-temperature growth of well-aligned $\mathrm{ZnO}$ nanorods by chemical vapor deposition, Advanced Materials 14(3) (2002) 215-218. 
[19] B. Liu and H. C. Zeng, Hydrothermal synthesis of $\mathrm{ZnO}$ nanorods in the diameter regime of $50 \mathrm{~nm}$, Journal of the American Chemical Society 125(15) (2003) 4430-4431.

[20] Y. W. Heo, D. P. Norton, L. C. Tien, Y. Kwon, B. S. Kang, F.Ren, S. J. Pearton, J. R. LaRoche, $\mathrm{ZnO}$ nanowire growth and devices, Materials Science of Engineering: R: Reports 47(1-2) (2004) 1-47.

[21] C. J. Chang, S. T. Hung, C. K. Lin, C. Y. Chen, E. H. Kuo, Selective growth of ZnO nanorods for gas sensors using ink-jet printing and hydrothermal processes, Thin Solid Films 519 (2010) $1693-1698$.

[22] R. Kitsomboonloha, S. Baruah, M. T. Z. Myint, V. Subramanian, J. Dutta, Selective growth of zinc oxide nanorods on inkjet printed seed patterns, Journal of Crystal Growth 311(8) (2009) $2352-2358$.

[23] L. Vayssieres, Growth of arrayed nanorods and nanowires of $\mathrm{ZnO}$ from aqueous solutions, Advanced Materials 15(5) (2003) 464-466.

[24] Y. W. Wang, L. D. Zhang, G. Z. Wang, X. S. Peng, Z.Q. Chu, C.H. Liang, Catalytic growth of semiconducting zinc oxide nanowires and their photoluminescence properties, Journal of Crystal Growth 234(1) (2002) 171-175.

[25] H. Z. Zhang, X. C. Sun, R. M. Wang, D. P. Yu, Growth and formation mechanism of coriented $\mathrm{ZnO}$ nanorod arrays deposited on glass, Journal of Crystal Growth 269(2-4) (2004) 464-471.

[26] Y. Sun, G.M. Fuge, M.N.R. Ashfold, Growth mechanisms for ZnO nanorods formed by pulsed laser deposition, Superlattices Microstructures 39(1-4) (2006) 33-40.

[27] Th. Pauporté, D. Lincot, Hydrogen Peroxide Oxygen Precursor for Zinc Oxide Electrodeposition I. Deposition in Perchlorate Medium, Journal of the Electrochemical Society 148(4) (2001) C310.

[28] Th. Pauporté, D. Lincot, B. Viana, F. Pellé, Toward laser emission of epitaxial nanorod arrays of $\mathrm{ZnO}$ grown by electrodeposition, Applied Physics Letters 89 (2006) 233112.

[29] W.J. Li, E.W. Shi, W.Z. Zhong, Z.W. Yin, Growth mechanism and growth habit of oxide crystals, Journal of Crystal Growth 203(1) (1999) 186-196.

[30] E.R. Carraway, A.J. Hoffman, M.R. Hoffmann, Photocatalytic oxidation of organic acids on quantum-sized semiconductor colloids, Environmental Science and Technology 28 (1994) 786-793. 
[31] S. Herminghaus, Roughness-induced non-wetting, Europhysics Letters 52(2) (2000) 165170.

[32] M.T.Z. Myint, R. Kitsomboonloha, S. Baruah, J. Dutta, Superhydrophobic surfaces using selected zinc oxide microrod growth on ink-jetted patterns, Journal of Colloid and Interface Science 354 (2011) 810-815.

[33] J. Li, Y. Yang, F. Zha, Z. Lei, Facile fabrication of superhydrophobic ZnO surfaces from high to low water adhesion, Materials Letters 75 (2012) 71-73.

[34] C. Florica, N. Preda, M. Enculescu, I. Zgura, M. Socol, I. Enculescu, Superhydrophobic ZnO networks with high water adhesion, Nanoscale Research Letters 2014, 9:385.

[35] J. Li, X. Liu, Y. Ye, J. Chen, Gecko-inspired synthesis of superhydrophobic ZnO surfaces with high water adhesion, Colloids and Surfaces A: Physicochemical and Engineering aspects 384(1-3) (2011) 109-114.

[36] B. Bhushan, Biomimetics: lessons from nature-an overview, Philosophical Transactions of the Royal Society A 367 (2009) 1445-1486.

[37] Y. A. Autumn, S. T. Liang, W. Hsieh, W. P. Zesch, T. W. Chan, R. Kenny, R. J. Fearing, Full, adhesive force of a single gecko foot-hair. Nature 405 (2000) 681-685.

[38] B. Bhushan, E. K. Her, Fabrication of superhydrophobic surfaces with high and low adhesion inspired from rose petal, Langmuir 26(11) (2010) 8207-8217.

[39] L. Feng, Y. Zhang, J. Xi, Y. Zhu, N. Wang, F. Xia, L. Jiang, Petal Effect: A Superhydrophobic State with High Adhesive Force, Langmuir 24(8) (2008) 4114-4119.

[40] J. Li, X. Liu, Y. Ye, H. Zhou H, J. Chen, A facile solution-immersion process for the fabrication of superhydrophobic surfaces with high water adhesion, Materials Letters 66(1) (2012) 321-323.

[41] M. Jin, X. Feng, L. Feng, T. Sun, J. Zhai, T. Li, L. Jiang, Superhydrophobic Aligned Polystyrene Nanotube Films with High Adhesive Force, Advanced Materials17(16) (2005) 1977-1981.

[42] X. Hong, X. Gao, L. Jiang, Application of superhydrophobic surface with high adhesive force in no lost transport of superparamagnetic microdroplet, Journal of the American Society 129 (2007) 1478-1479.

[43] A. Winkleman, G. Gotesman, A. Yoffe, R. Naaman, Immobilizing a drop of water: fabricating highly hydrophobic surfaces that pin water droplets, Nano Letters 8(4) (2008) 1241-1245. 
[44] T. Young, An essay on the Cohesion of Fluids, Philosophical Transactions of the Royal Society B 95 (1805) 65-87.

[45] R. N. Wenzel, Resistance of solid surfaces to wetting by water. Industrial and Engineering Chemistry 28 (1936) 988-994.

[46] A.B.D. Cassie, S. Baxter, Wettability of porous surfaces, Transactions of Faraday Society 40 (1944) 546-551.

[47] A. Shastry, M.J. Case, K.F. Bohringer, Directing droplets using microstructured surfaces, Langmuir 22(14) (2006) 6161-6167.

[48] P. Joseph, C. Cottin-Bizonne, J.M. Benoît, C. Ybert, C. Journet, P. Tabeling, L.Bocquet, Slippage of Water Past Superhydrophobic Carbon Nanotube Forests in Microchannels, Physical Review Letters 97(15) (2006) 1-23.

[49] X. Zhua, Z. Zhanga, X. Mena, J. Yanga, X. Xu, Fabrication of an intelligent superhydrophobic surface based on $\mathrm{ZnO}$ nanorod arrays with switchable adhesion property, Applied Surface Science 256 (2010) 7619-7622.

[50] Y. Shi, W. Yang, X. Feng, Y. Wang, G. Yue, Fabrication of superhydrophobic ZnO nanorod surface with corrosion resistance via combining thermal oxidation and surface modification, Materials Letters151(2015)24-27.

[51] M. Xue, W. Wang, F. Wang, J. Ou, W. Li, Design and understanding of superhydrophobic $\mathrm{ZnO}$ nanorod arrays with controllable water adhesion, Surface \& Coatings Technology 258 (2014) 200-205.

[52] M. T. Z. Myint, G. L. Hornyak, J. Dutta, One pot synthesis of opposing 'rose petal' and 'lotus leaf'superhydrophobic materials with zinc oxide nanorods, Journal of Colloid and Interface Science 415 (2014) 32-38.

[53] Y. Tang, J. Chen, D. Greiner, L. Aé, R. Baier, J. Lehmann, S. Sadewasser, and M. Ch. LuxSteiner, J. Phys. Chem. C 115, 5239 (2011).

[54] J. Elias, R. Tena-Zaera, and C. Lévy-Clément, Thin Solid Films 515, 8553 (2007).

[55] W. Ludwig, W. Ohm, J. M. Correa-Hoyos, Y. M. Zhao, M. C. Lux-Steiner, and S. Gledhill, Phys. Status Solidi A 8, 1557 (2013).

[56] M. Izaki, T. Omi, Electrolyte Optimization for Cathodic Growth of Zinc Oxide Films, Journal of the Electrochemical Society 143(3) (1996) L53-55. 
[57] M. Izaki, T. Omi, Transparent Zinc Oxide Films Chemically Prepared from Aqueous Solution, Journal of the Electrochemical Society 144(1) (1997) L3-5.

[58] M. Izaki, T. Omi, Transparent zinc oxide films prepared by electrochemical reaction, Applied Physics Letters 68(17) (1996) 2439-2440.

[59] B. D. Cullity, Elements of X-Ray Diffraction, second ed., Addison Wesley, reading, MA, 1978.

[60] P. Scherrer, Bestimmung der Grösse und der inneren Struktur von Kolloidteilchen mittels Röntgenstrahlen, Nachr. Ges. Wiss. Göttingen, Mathematisch-Physikalische Klasse 26 (1918) 98-100.

[61] J.I. Langford and A.J.C. Wilson, Scherrer after Sixty Years: A Survey and Some New Results in the Determination of Crystallite Size, Journal of Applied Crystallography 11 (1978) 102113.

[62] K. Y. Yeh, K. H. Cho, Y. H. Yeh, A. Promraksa, C. H. Huang, C. C. Hsu, L. J. Chen, Observation of the rose petal effect over single- and dual-scale roughness surfaces, Nanotechnology 25 (2014) 345303.

[63] V. Khranovskyy, T. Ekblad, R. Yakimova, L. Hultman, Surface morphology effects on the light-controlled wettability of $\mathrm{ZnO}$ nanostructures, Applied Surface Science 258 (2012) 8146.

[64] L. Yao, M. Zheng, C. Li, L. Ma, W. Shen, Facile synthesis of superhydrophobic surface of $\mathrm{ZnO}$ nanoflakes: chemical coating and UV-induced wettability conversion, Nanoscale Research Letters 7:216 (2012).

[65] Y.J. Li, X. D. Li, J. W. Li, J. Yin, Photocatalytic degradation of methyl orange by $\mathrm{TiO}_{2}$-coated activated carbon and kinetic study, Water Research 40(6) (2006) 1119-1126. 